\title{
Racial disparities in trajectories of dental caries experience
}

\author{
Jersey Liang ${ }^{1}$, Bei $\mathrm{Wu}^{2}$, Brenda Plassman ${ }^{3}$, \\ Joan Bennett ${ }^{1}$ and James Beck ${ }^{4}$ \\ ${ }^{1}$ University of Michigan, Ann Arbor, MI, \\ USA, ${ }^{2}$ Duke University School of Nursing \\ and Global Health Institute, Durham, NC, \\ USA, ${ }^{3}$ Duke University Medical Center, \\ Durham, NC, USA, ${ }^{4}$ University of North \\ Carolina, Chapel Hill, NC, USA
}

Liang J, Wu B, Plassman B, Bennett J, Beck J. Racial disparities in trajectories of dental caries experience. Community Dent Oral Epidemiol 2013; 41: 517-525. (C) 2013 John Wiley \& Sons A/S. Published by John Wiley \& Sons Ltd
Abstract - Objectives: This study charted the trajectories of dental caries, including decayed teeth, missing teeth and filled teeth among older Americans over a 5-year period. In particular, it focused on racial differences in the levels of and rates of change in dental caries experience. Methods: Data came from the Piedmont Dental Study. The sample included 810 older Americans who were dentate at the baseline with up to 4 repeated observations between 1988 and 1994. Hierarchical linear models were employed in depicting intrapersonal and interpersonal differences in dental caries experience. Results: Different measures of caries outcomes exhibited distinct trajectories. On average, the number of decayed teeth decreased over time, whereas missing teeth increased. In contrast, the number of filled teeth remained stable during a 5-year period. Relative to their white counterparts, older black Americans had more decayed teeth and missing teeth but fewer filled teeth. Blacks and whites differed in the levels of dental caries but not in their rates of change except for missing teeth. Even when demographic and socioeconomic attributes were adjusted, racial variations in dental caries experience remained significant. Conclusions: Although significantly correlated, various dental caries outcomes move along different paths over time. In view of the persistent racial disparities in dental caries trajectories, future interventions to minimize such variations among older Americans in the levels of and the rates of change in dental caries experience are clearly warranted.
Key words: caries; oral health

Jersey Liang, University of Michigan, Ann Arbor, MI, USA

Tel.: 734-936-1303

Fax: 734-764-4338

e-mail: jliang@umich.edu

Submitted 9 August 2012; accepted 6 February 2013
Oral health among older adults is a high priority in public health because of the growing population of older Americans, the disproportionate burden of oral diseases of older compared to younger Americans, and disparities in access to dental care $(1,2)$. Compared with younger individuals, elderly people have a higher prevalence of missing teeth, dental caries and periodontal diseases (3). Although edentulism in old age has declined, the prevalence of decayed teeth, filled teeth and periodontal disease have increased, as more of them have retained their natural teeth $(3,4)$. A lifetime of dental disease experience, tooth loss, medical conditions and medications adds to the complexity of oral care for older people. Thus, demand for dental care by older adults has increased substantially (2). Nonetheless, significant disparities persist in the access to dental care due to limited insurance coverage, a shortage of dental care providers, and increasing disability in old age, particularly in lower income and minority groups $(2,5,6)$.

Although there is an increasing volume of research on socioeconomic disparities in oral health (7-9), few studies have focused on racial differences in the dynamics of dental caries experience among older adults. There is some evidence that older black Americans have more missing teeth and decayed teeth than white Americans (3, 10-13). However, much of the current research is based on cross-sectional data, which do not allow 
the researcher to distinguish intrapersonal changes in dental caries over time from interpersonal differences (across age, gender and race/ethnicity).

The few longitudinal studies of dental caries experience among older adults available have focused on transitions between two points in time, particularly the incidence of dental diseases and their risk factors $(14,15)$. This approach does not fully capture the dynamic nature of dental caries experience, as it provides no basis for distinguishing among alternative functional forms of growth curves or trajectories (16). A more complete understanding of the dynamics of dental caries experience requires an analysis of trajectories in terms of their levels and rates of change.

In this study, we offer quantitative estimates of racial disparities in the trajectories of dental caries using longitudinal data derived from a populationbased sample of older Americans during a 5-year period (1988-1994). Based on a framework of social determinants of oral health, we view racial differences in dental caries experience trajectories as a result of social stratification $(17,18)$ with several underlying mechanisms including: (i) less advantaged socioeconomic circumstances, (ii) constraints placed on life style choices or (iii) stress as a result of perception of discrimination $(19,20)$. Extrapolating from prior research, we pose three hypotheses regarding racial differences in the trajectories of dental caries over time. First, the number of untreated decayed teeth decreases over time, partially due to an increase in missing teeth in old age $(14,15)$. In addition, older black Americans have more decayed teeth than their white counterparts $(21,22)$, although the rate of increase in decayed teeth does not differ between blacks and whites $\left(\mathrm{H}_{1}\right)$. Second, the number of missing teeth increases over time in old age in a linear or nonlinear fashion $(23,24)$, with black Americans having more missing teeth and a greater rate of increase than white Americans (25) $\left(\mathrm{H}_{2}\right)$. Third, white Americans have more filled teeth than black Americans (26), but the rate of increase is similar for both groups, partially reflecting more missing teeth and less access to dental care among blacks $\left(\mathrm{H}_{3}\right)$.

\section{Materials and methods}

\section{Design and sample}

Data came from the Piedmont Dental Study (PDS), a random subsample of the parent study, the Duke Established Populations for Epidemiologic Studies of the Elderly (Duke EPESE), which was based on a stratified random clustered sample of all people age 65 and over in the five adjacent counties in the Piedmont area of North Carolina in 1986. The PDS began in 1988 with a random subsample of 810 dentate individuals from the Duke EPESE. These respondents were asked to participate again at 18 months, 36 months and 60 months follow-up, except for those who became edentulous or died. The final analytical sample consisted of 810 participants at the baseline with 2926 observations over a period of 5 years.

\section{Measures}

Numbers of decayed, missing and filled teeth were obtained from dental examinations in 1988, 1990, 1991 and 1994. From Duke EPESE in 1988, measures of social stratification including age, gender ( male $=1)$ and race (white $=1$ ) were acquired. In addition, education was indexed by years of schooling, whereas household income at the baseline was indicated by quartiles, with the first quartile reflecting the lowest income. A more extended description of the sample, collection of clinical data, and interview measures can be found elsewhere $(22,27)$.

\section{Data analysis}

In this study, we offer quantitative estimates of racial disparities in the trajectories of dental caries by using longitudinal data derived from a population-based sample of older Americans during a 5year period (1988-1994). Hierarchical linear models (HLMs) were used to chart the trajectories of decayed, missing and filled teeth (28). The counts for the dependent variables indicating dental caries were positively skewed and contained many zeros partially due to the large proportions of individuals with no decayed or filled teeth. Statistically, it might be better to treat them as ordinal instead of continuous variables $(29,30)$. We undertook our analyses by treating these measures as both continuous and ordinal variables and obtained very similar results. For the ease of presentation, we include the results based on continuous variables.

The intra-individual differences in dental caries (e.g., number of decayed teeth) were modelled as follows in the Level-1 equation:

$$
\mathrm{Y}_{\mathrm{iT}}=\pi_{0 \mathrm{i}}+\pi_{1 \mathrm{i}} \text { Time }+\varepsilon_{\mathrm{iT}},
$$

where $\mathrm{Y}_{\mathrm{iT}}$ is the number of decayed teeth of individual $i$ at time T. $\pi_{0 \mathrm{i}}$ is the intercept (i.e. level) and $\pi_{1 \mathrm{i}}$ is the slope (i.e. rate of change) over time. Time 
Table 1. Dental caries experience over time

\begin{tabular}{|c|c|c|c|c|c|c|}
\hline & \multicolumn{2}{|l|}{ Black } & \multicolumn{2}{|l|}{ White } & \multicolumn{2}{|l|}{ Total } \\
\hline & Mean (SD) & $N$ & Mean (SD) & $N$ & Mean (SD) & $N$ \\
\hline \multicolumn{7}{|l|}{ Decayed teeth } \\
\hline Baseline 1988 & $2.5(3.5)$ & 448 & $0.8(1.9)$ & 362 & $1.7(3.0)$ & 810 \\
\hline 18 months follow-up & $2.1(3.1)$ & 337 & $0.8(1.7)$ & 285 & $1.5(2.6)$ & 622 \\
\hline 36 months follow-up & $2.1(2.9)$ & 234 & $0.8(1.4)$ & 218 & $1.5(2.4)$ & 452 \\
\hline 60 months follow-up & $1.8(3.1)$ & 188 & $0.6(1.6)$ & 175 & $1.2(2.6)$ & 363 \\
\hline \multicolumn{7}{|l|}{ Missing teeth } \\
\hline Baseline 1988 & $15.3(7.9)$ & 448 & $11.8(7.8)$ & 362 & $13.7(8.0)$ & 810 \\
\hline 18 months follow-up & $16.0(8.2)$ & 337 & $11.8(8.1)$ & 285 & $14.1(8.4)$ & 622 \\
\hline 36 months follow-up & $15.7(7.5)$ & 234 & $11.5(7.7)$ & 218 & $13.6(7.9)$ & 452 \\
\hline 60 months follow-up & $16.4(7.6)$ & 188 & $11.8(7.9)$ & 175 & $14.2(8.0)$ & 363 \\
\hline \multicolumn{7}{|l|}{ Filled teeth } \\
\hline Baseline 1988 & $2.3(3.8)$ & 448 & $10.5(7.2)$ & 362 & $6.0(6.9)$ & 810 \\
\hline 18 months follow-up & $2.4(3.9)$ & 337 & $10.9(7.1)$ & 285 & $6.3(7.0)$ & 622 \\
\hline 36 months follow-up & $2.7(1.2)$ & 234 & $10.8(6.9)$ & 218 & $6.6(7.0)$ & 452 \\
\hline 60 months follow-up & $2.6(3.8)$ & 188 & $11.1(7.0)$ & 175 & $6.7(7.0)$ & 363 \\
\hline
\end{tabular}

is the distance (in years) of assessment from the baseline in 1988, when the respondent was first examined, and $\varepsilon_{\mathrm{iT}}$ is a random error. Time was centred on its grand mean (around 2.5 years). We also explored nonlinear changes with time by incorporating a quadratic term of the time variable (i.e. Time $_{\mathrm{ij}}^{2}$ ) in Eq. (1).

Inter-personal variations in the trajectory of decayed teeth (i.e., intercept and slope) were specified in the Level-2 equation:

$$
\pi_{\mathrm{pi}}=\beta_{\mathrm{p} 0}+\Sigma \beta_{\mathrm{pq}} \mathrm{X}_{\mathrm{qi}}+\mathrm{r}_{\mathrm{pi}}
$$

where $\mathrm{X}_{\mathrm{qi}}$ is the $q$ th time-constant covariate (e.g. age-at-baseline, gender, education) associated with individual $i$, and $\beta_{p q}$ represents the effect of variable $X_{q}$ on the $p$ th growth parameter $\left(\pi_{p}\right)$ (i.e. intercept and slope). $r_{p i}$ is a random effect with a mean of 0 . All time-constant covariates (Level 2) were not centred. Bayesian information criterion (BIC) was used as the goodness-of-fit index to select the optimal models. All models were fitted by using HLM version 6.06 (31).

To minimize the loss of participants due to item nonresponse, multiple imputation (MI) was undertaken. In particular, five complete data sets were imputed with the NORM software developed by Schafer (32) and analyses were run on each of these five data sets with parameter estimates derived by averaging across five imputations and by adjusting for their variance. As a major advantage, multilevel models can include every participant in the estimation, regardless how many observations one contributed to the data set. With reference to attrition, multilevel models are predicated on the assumption of missing at random (MAR) that the probability of missing depends upon only the observed data for either the covariates or the outcome variables, hence permitting valid inference (28). In addition to MAR, to adjust for the selection bias due to attrition, we included dummy variables in the Level-2 equation to differentiate those with complete data during the period of study from those who dropped out of the study. They were viewed as confounding variables instead of predictors of dental caries experience.

\section{Results}

The numbers of decayed teeth and missing teeth were substantially higher among blacks than white Americans, whereas the reverse was true for filled teeth (Table 1). In addition, the number of observations at the baseline was 810 which declined to 363 at the 60-month follow-up, largely due to edentulism, attrition or mortality. The reduction of mean number of missing teeth at 36 months follow-up may be a result of increasing number of individuals who became edentulous and thus were removed from the sample. At the same time, black and white participants did not differ in age and sex composition, although there were significant racial disparities in education and household income. As mentioned previously, we controlled the bias due to mortality and attrition by relying on the assumption of MAR and adjusting for attrition, death and proxy interview in our models (Table 2) 
Liang et al.

Table 2. Descriptive statistics of the PDS sample at the baseline

\begin{tabular}{|c|c|c|c|c|c|c|c|c|c|}
\hline & \multicolumn{3}{|c|}{ Black $55.3 \%(N=448)$} & \multicolumn{3}{|c|}{ White $44.7 \%(N=362)$} & \multicolumn{3}{|c|}{ Total $(N=810)$} \\
\hline & Mean & SD & $\%$ & Mean & SD & $\%$ & Mean & SD & $\%$ \\
\hline Age (Years) & 73.2 & 5.6 & & 73.5 & 5.8 & & 73.3 & 5.7 & \\
\hline \multicolumn{10}{|l|}{ Sex } \\
\hline Female & & & $59.6 \%$ & & $58.8 \%$ & & & & $59.3 \%$ \\
\hline Male & & & $40.4 \%$ & & $41.2 \%$ & & & & $40.7 \%$ \\
\hline Education (Years) ${ }^{*}$ & 7.9 & 4.4 & & 11.8 & 3.7 & & 9.7 & 4.5 & \\
\hline \multicolumn{10}{|c|}{ Household income (In quartiles) } \\
\hline 1st (Lowest) & & $47.3 \%$ & & & $11.0 \%$ & & & $31.1 \%$ & \\
\hline 2nd & & $30.1 \%$ & & & $18.2 \%$ & & & $24.8 \%$ & \\
\hline 3rd & & $14.7 \%$ & & & $32.3 \%$ & & & $22.6 \%$ & \\
\hline 4th (Highest) & & $7.8 \%$ & & & $38.4 \%$ & & & $21.5 \%$ & \\
\hline
\end{tabular}

*Mean difference test significant at $P<0.001$; $* *$ chi-square test significant at $P<0.001$.

Table 3. Multilevel regression analysis of the trajectory of decayed teeth

\begin{tabular}{|c|c|c|c|c|c|c|c|c|}
\hline \multirow[b]{2}{*}{ Covariate } & & & \multicolumn{2}{|l|}{ Model 1} & \multicolumn{2}{|l|}{ Model 2} & \multicolumn{2}{|c|}{ Model 3} \\
\hline & & & Coef & $P$-value & Coef & $P$-value & Coef & $P$-value \\
\hline \multicolumn{9}{|l|}{ Fixed effect } \\
\hline \multicolumn{9}{|c|}{ For intercept, $\pi_{0}$} \\
\hline Intercept & & & 1.604 & $<0.001$ & 1.961 & 0.065 & 4.484 & $<0.001$ \\
\hline Dropout for & ersus comp & & & & 0.019 & 0.925 & -0.016 & 0.936 \\
\hline Returned aft & out (versus & te data) & & & 0.210 & 0.504 & 0.097 & 0.746 \\
\hline Death (versu & lete data) & & & & 0.795 & 0.019 & 0.665 & 0.046 \\
\hline Proxy intervi & oxy versus 1 & xy) & & & 0.733 & 0.153 & 0.558 & 0.265 \\
\hline Age (in years & & & & & -0.002 & 0.875 & -0.019 & 0.207 \\
\hline Sex (Male ve & male) & & & & 0.399 & 0.034 & 0.685 & $<0.001$ \\
\hline Race (White & Black) & & & & -1.311 & $<0.001$ & -0.520 & 0.008 \\
\hline Education ye & years) & & & & & & -0.047 & 0.062 \\
\hline Household in & in quartiles & & & & & & -0.535 & $<0.001$ \\
\hline \multicolumn{9}{|c|}{ For linear time slope, $\pi_{1}$} \\
\hline Intercept & & & -0.050 & 0.014 & -0.419 & 0.101 & -0.366 & 0.206 \\
\hline Dropout for & ersus comp & & & & -0.050 & 0.419 & -0.046 & 0.455 \\
\hline Returned aft & out (versus & te data) & & & -0.112 & 0.093 & -0.111 & 0.101 \\
\hline Death (versu & lete data) & & & & -0.032 & 0.737 & -0.038 & 0.692 \\
\hline Proxy intervi & oxy versus 1 & xy) & & & 0.062 & 0.548 & 0.068 & 0.526 \\
\hline Age (in years & & & & & 0.005 & 0.154 & 0.004 & 0.246 \\
\hline Sex (Male ve & male) & & & & -0.006 & 0.884 & 0.007 & 0.869 \\
\hline Race (White & Black) & & & & 0.076 & 0.059 & 0.088 & 0.063 \\
\hline Education ye & years) & & & & & & 0.004 & 0.583 \\
\hline Household in & in quartiles & & & & & & -0.021 & 0.475 \\
\hline Random effect & Variance & $P$-value & \multicolumn{2}{|c|}{ Variance } & $P$-value & \multicolumn{2}{|c|}{ Variance } & $P$-value \\
\hline Intercept & 6.500 & $<0.001$ & \multicolumn{2}{|c|}{5.855} & $<0.001$ & \multicolumn{2}{|c|}{5.488} & $<0.001$ \\
\hline
\end{tabular}

\section{Trajectory of decayed teeth}

Consistent with our hypothesis $\left(\mathrm{H}_{1}\right)$, the number of untreated decayed teeth decreased slightly over time (Model 1, Table 3). In addition, white Americans had fewer decayed teeth $(b=-1.311$; confidence interval at $95 \%$ level or $\mathrm{CI}_{95}=-1.663$, $-0.969)$, whereas there was no significant racial difference in the rate of change $(b=0.076$; $\mathrm{CI}_{95}=-0.003$, 0.154) (Model 2, Table 3). The number of decayed teeth decreased from 1.0 to 0.9 for whites, whereas it decreased from 2.4 to 2.0 for blacks (Fig. 1).

Racial difference in decayed teeth attenuated somewhat but remained significant when age, gender, education and income were controlled (Model 3, Table 3). In addition to racial differences, men had more decayed teeth, whereas those with higher household income had fewer 


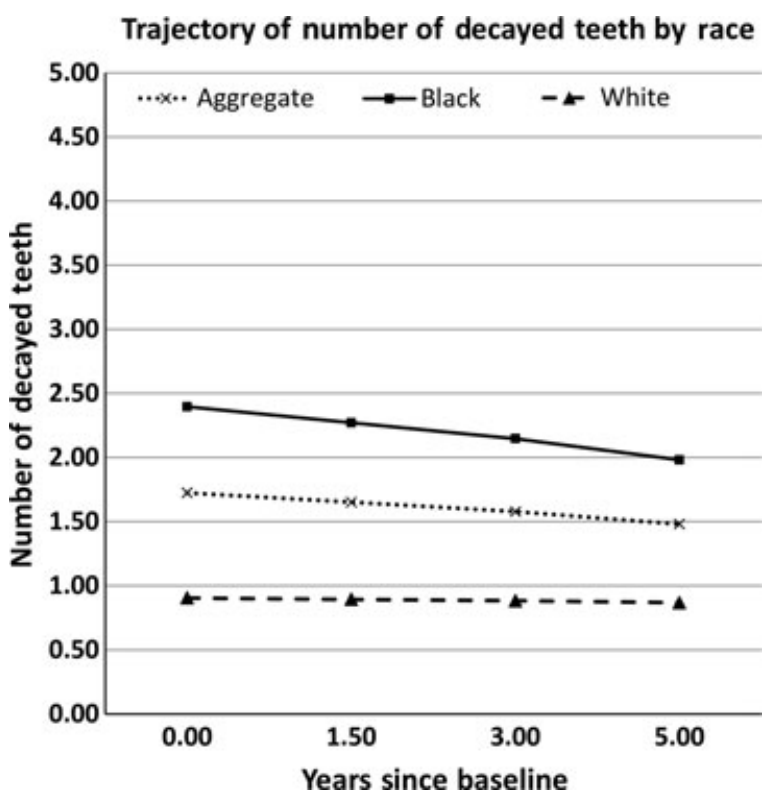

Fig. 1. Racial differences in number of decayed teeth (Model 2).

decayed teeth (Model 3, Table 3). Those who died during the period of observation had more decayed teeth, even with demographic and socioeconomic attributes controlled (Models 3 in Table 3).

\section{Trajectory of missing teeth}

In accordance with $\mathrm{H}_{2}$, the number of missing teeth increased over time (Model 1, Table 4). Relative to blacks, whites had not only fewer missing teeth $\left(\mathrm{b}=-4.100 ; \mathrm{CI}_{95}=-5.178,-3.021\right)$ but also a lower rate of increase $\left(\mathrm{b}=-0.224 ; \mathrm{CI}_{95}=-0.315,-0.132\right)$ over time (Model 2, Table 4). The number of missing teeth increased from 11.8 to 12.9 for whites, whereas it increased from 15.3 to 17.6 for blacks (Fig. 2).

With education and income controlled, racial differences in the level of missing teeth and the rate of change remained significant (Model 3, Table 4). Furthermore, older age was associated with a greater number of missing teeth and those with higher household income had fewer missing teeth (Model 3, Table 4). Finally, even with demographic and socioeconomic characteristics adjusted, those who dropped out during the period of observation had more missing teeth (Model 3, Table 4), whereas mortality and proxy interview did not appear to matter.

Table 4. Multilevel regression analysis of the trajectory of missing teeth

\begin{tabular}{|c|c|c|c|c|c|c|c|c|}
\hline \multirow[b]{2}{*}{ Covariates } & & & \multicolumn{2}{|c|}{ Model 1} & \multicolumn{2}{|l|}{ Model 2} & \multicolumn{2}{|c|}{ Model 3} \\
\hline & & & Coef & $P$-value & Coef & $P$-value & Coef & $P$-value \\
\hline \multicolumn{9}{|l|}{ Fixed effect } \\
\hline \multicolumn{9}{|c|}{ For intercept, $\pi_{0}$} \\
\hline Intercept & & & 14.529 & $<0.001$ & -6.109 & 0.087 & -0.757 & 0.838 \\
\hline Dropout for & rersus comp & ta) & & & 2.101 & 0.003 & 1.991 & 0.004 \\
\hline Returned aft & out (versus & ete data) & & & 1.181 & 0.183 & 0.914 & 0.302 \\
\hline Death (versu & lete data) & & & & 1.024 & 0.194 & 0.767 & 0.323 \\
\hline Proxy intervi & oxy versus & xy) & & & -0.534 & 0.623 & -1.033 & 0.356 \\
\hline Age (in year & & & & & 0.295 & $<0.001$ & 0.263 & $<0.001$ \\
\hline Sex (Male ve & male) & & & & -0.209 & 0.717 & 0.270 & 0.658 \\
\hline Race (White & Black) & & & & -4.100 & $<0.001$ & -2.409 & $<0.001$ \\
\hline Education ye & years) & & & & & & -0.165 & 0.059 \\
\hline Household it & (in quartiles & & & & & & -0.953 & 0.010 \\
\hline \multicolumn{9}{|c|}{ For linear time slope, $\pi_{1}$} \\
\hline Intercept & & & 0.320 & $<0.001$ & 0.752 & 0.025 & 0.833 & 0.025 \\
\hline Dropout for & rersus comp & & & & 0.126 & 0.099 & 0.122 & 0.106 \\
\hline Returned aft & out (versus & ete data) & & & 0.142 & 0.110 & 0.132 & 0.139 \\
\hline Death (versu & lete data) & & & & -0.006 & 0.927 & -0.007 & 0.916 \\
\hline Proxy intervi & oxy versus & xy) & & & -0.063 & 0.604 & -0.109 & 0.349 \\
\hline Age (in years & & & & & -0.005 & 0.233 & -0.005 & 0.278 \\
\hline Sex (Male ve & male) & & & & 0.093 & 0.084 & 0.067 & 0.191 \\
\hline Race (White & Black) & & & & -0.224 & $<0.001$ & -0.204 & 0.001 \\
\hline Education ye & years) & & & & & & -0.015 & 0.101 \\
\hline Household i & (in quartiles & & & & & & 0.027 & 0.447 \\
\hline Random effect & Variance & $P$-value & \multicolumn{2}{|c|}{ Variance } & $P$-value & \multicolumn{2}{|c|}{ Variance } & $P$-value \\
\hline Intercept & 66.489 & $<0.001$ & \multicolumn{2}{|c|}{59.567} & $<0.001$ & \multicolumn{2}{|c|}{57.888} & $<0.001$ \\
\hline
\end{tabular}




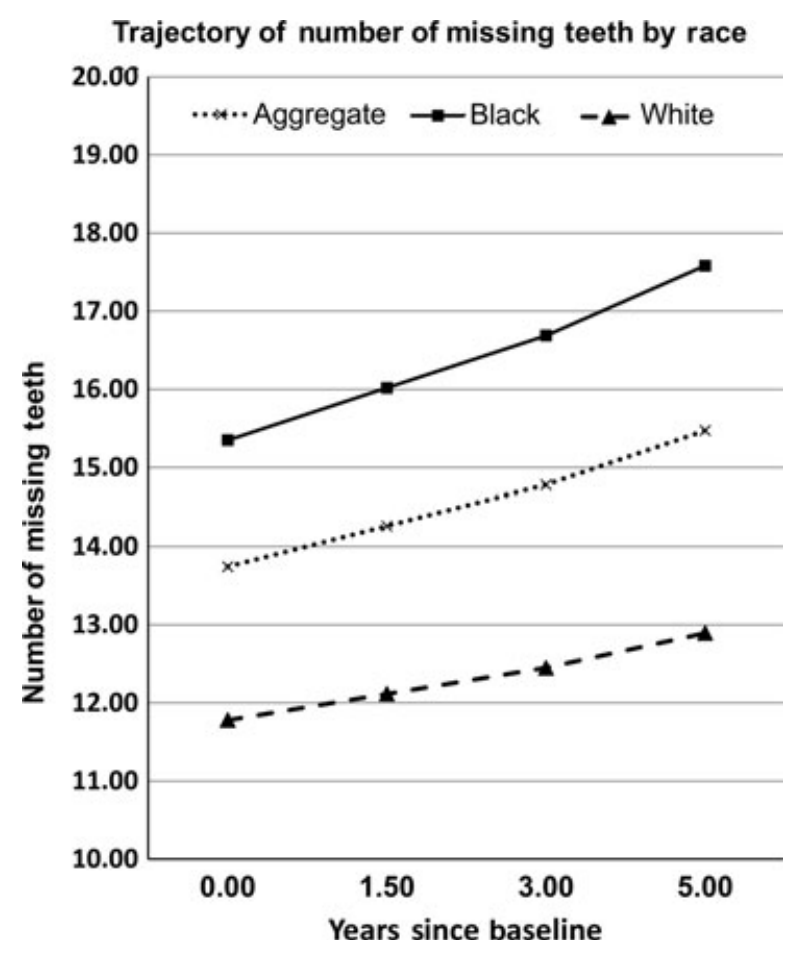

Fig. 2. Racial differences in number of missing teeth (Model 2).

\section{Trajectory of filled teeth}

In contrast with its hypothesized increase $\left(\mathrm{H}_{3}\right)$, the number of filled teeth decreased slightly over time (Model 1, Table 5), which may be explained by the heterogeneity in demographic attributes (Model 2, Table 5). Nonetheless, there is evidence in support of $\mathrm{H}_{3}$ that whites had more filled teeth than blacks $\left(b=7.982 ; \mathrm{CI}_{95}=7.175,8.788\right)$, and this difference remained stable over time $\left(\mathrm{b}=-0.014 ; \mathrm{CI}_{95}=\right.$ $-0.085,0.058$ ) (Model 2, Table 5; Fig. 3). When education and income were adjusted, racial differences in the level of filled teeth attenuated but remained significant (Model 3, Table 5). Older age was associated with fewer filled teeth but this effect was mitigated when socioeconomic attributes were included (Model 3, Table 5). Those with higher education and higher household income had more filled teeth but with the same rate of increase (Model 3, Table 5). Finally, those who dropped out, died and had at least one proxy interview did not differ from other respondents in the number of filled teeth, when demographic and socioeconomic attributes were adjusted (Model 3 in Table 5).

\section{Discussion}

Previous research based on PDS focused on racial differences in the incidences of tooth loss and caries in conjunction with their annual rates of increment (22, 33-38). Whereas prior research has documented racial disparities in dental caries experience at one or two points in time, we are able to depict racial variations in the level of dental caries experience and its rate of change over an extended period of time. During a period of 5 years, the number of untreated decayed teeth decreased; the number of missing teeth increased; and the number of filled teeth stayed stable. Older black Americans fare poorly relative to their white counterparts in the trajectories of dental caries experience, and these disparities persist even with SES adjusted.

Given that decayed, missing and filled teeth exhibit distinct trajectories, it may be inappropriate to combine measures of these three conditions to form the widely used index of DMFT (i.e. decayed, missing and filled teeth). This caution is further reinforced by the fact that at the baseline, the number of filled teeth was negatively correlated with missing teeth $(\mathrm{r}=-0.488, P<0.001)$ and decayed teeth $(\mathrm{r}=-0.344, \quad P<0.001)$, whereas missing teeth was uncorrelated with decayed teeth $(\mathrm{r}=-0.008, P>0.05)$. Moreover, good, self-rated oral health was negatively correlated with missing teeth $(\mathrm{r}=-0.237, P<0.001)$ and decayed teeth $(\mathrm{r}=-0.218, P<0.001)$ but positively correlated with filled teeth $(\mathrm{r}=0.272, P<0.001)$. Finally, DMFT is dominated by the number of missing teeth because of its greater range in comparison with those for decayed and filled teeth. Hence, DMFT is less useful in assessing dental caries experience among older adults because of increasing missing teeth (26). DMFT, if used at all, should probably be presented in conjunction with its components. Nevertheless, our observations remain to be replicated with data from individuals under the age of 65 before our conclusion could be extended to nonelderly persons.

According to prior research, incidence of coronal and root caries was lower among older blacks relative to older whites (22). In contrast, we found that white Americans were less likely to have decayed teeth, whereas the rate of change did not differ significantly between the blacks and whites. These differences may be due to the fact that previous studies have classified decayed and filled surfaces as caries $(15,22)$, whereas in the present research, the number of decayed teeth was measured without including filled teeth in that once a decayed tooth was filled, it was classified only as a filled tooth. Indeed, as noted by Lawrence and associates 
Table 5. Multilevel regression analysis of the trajectory of filled teeth

\begin{tabular}{|c|c|c|c|c|c|c|c|c|}
\hline \multirow[b]{2}{*}{ Covariates } & & & \multicolumn{2}{|c|}{ Model 1} & \multicolumn{2}{|l|}{ Model 3} & \multicolumn{2}{|l|}{ Model 4} \\
\hline & & & Coef & $P$-value & Coef & $P$-value & Coef & $P$-value \\
\hline \multicolumn{9}{|l|}{ Fixed effect } \\
\hline \multicolumn{9}{|c|}{ For intercept, $\pi_{0}$} \\
\hline Intercept & & & 5.887 & $<0.001$ & 9.383 & $<0.001$ & -0.268 & 0.911 \\
\hline Dropout for $g$ & ersus comple & & & & -0.822 & 0.092 & -0.598 & 0.166 \\
\hline Returned afte & ut (versus c & te data) & & & -0.828 & 0.233 & -0.324 & 0.617 \\
\hline Death (versus & ete data) & & & & -1.028 & 0.054 & -0.531 & 0.254 \\
\hline Proxy intervi & xy versus n & & & & -0.917 & 0.074 & -0.042 & 0.936 \\
\hline Age (in years & & & & & -0.084 & 0.015 & -0.029 & 0.356 \\
\hline Sex (Male ver & nale) & & & & -0.537 & 0.177 & -1.279 & 0.001 \\
\hline Race (White & Black) & & & & 7.982 & $<0.001$ & 4.907 & $<0.001$ \\
\hline Education ye & years) & & & & & & 0.357 & $<0.001$ \\
\hline Household in & in quartiles) & & & & & & 1.533 & $<0.001$ \\
\hline \multicolumn{9}{|c|}{ For linear time slope, $\pi_{1}$} \\
\hline Intercept & & & -0.036 & 0.048 & -0.085 & 0.757 & -0.076 & 0.796 \\
\hline Dropout for $q$ & ersus comple & & & & 0.054 & 0.374 & 0.055 & 0.368 \\
\hline Returned afte & out (versus c & te data) & & & 0.010 & 0.848 & 0.010 & 0.845 \\
\hline Death (versus & ete data) & & & & 0.090 & 0.198 & 0.087 & 0.214 \\
\hline Proxy intervi & xy versus no & & & & -0.035 & 0.447 & -0.030 & 0.531 \\
\hline Age (in years & & & & & 0.001 & 0.895 & $<0.001$ & 0.918 \\
\hline Sex (Male ver & nale) & & & & 0.018 & 0.639 & 0.024 & 0.545 \\
\hline Race (White & 3lack) & & & & -0.014 & 0.707 & -0.008 & 0.837 \\
\hline Education ye & jears) & & & & & & 0.001 & 0.871 \\
\hline Household in & in quartiles) & & & & & & -0.006 & 0.766 \\
\hline Random effect & Variance & $P$-value & \multicolumn{2}{|c|}{ Variance } & $P$-value & \multicolumn{2}{|c|}{ Variance } & $P$-value \\
\hline Intercept & 45.566 & $<0.000$ & \multicolumn{2}{|c|}{28.831} & $<0.000$ & \multicolumn{2}{|c|}{22.475} & $<0.000$ \\
\hline
\end{tabular}

Trajectory of number of filled teeth by race

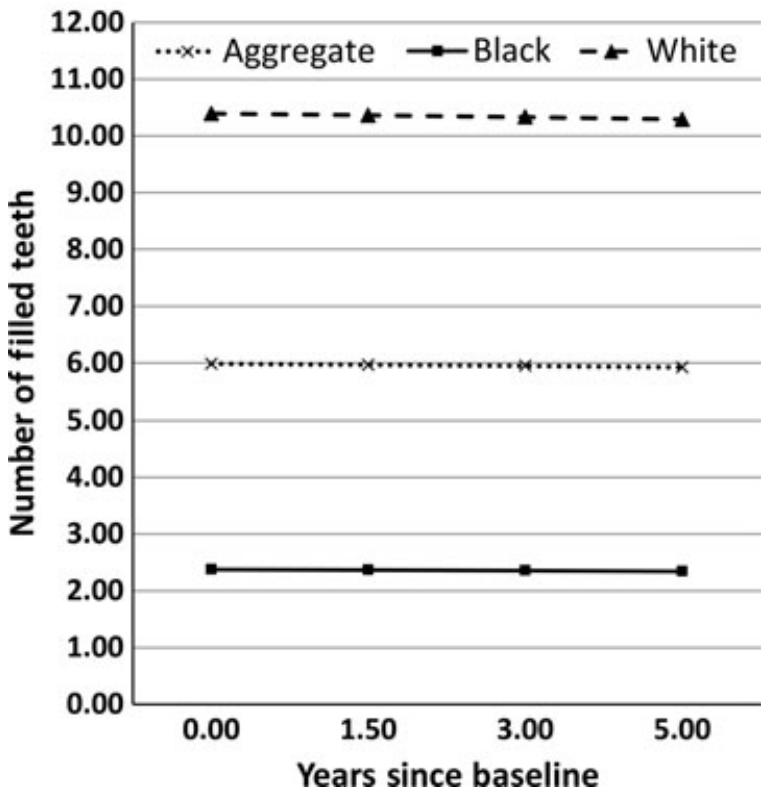

Fig. 3. Racial differences in number of filled teeth (Model 2).

(22), whereas blacks had more decayed root surfaces than whites, they had fewer decayed and filled root surfaces combined than their white counterparts. Furthermore, instead of focusing on incidence only, our analysis of trajectories took into account the prevalence and incidence of dental caries experience conditions over time.

Racial differences are confounded as well as mediated by a number of other factors (e.g. age, gender and education). Older age was correlated with more missing teeth over time, whereas men were likely to have more decayed teeth. Racial differences are partially mediated by socioeconomic status (SES) such as education and household income. However, even when SES was adjusted, racial variations in dental caries experience remained significant. To better understand the mechanism underlying racial differences in dental caries experience, further research on other confounding and mediating factors is required. They may include health system, environmental risk factors, health status, dental service use and health behaviours $(17,18)$. Future interventions to minimize racial variations among older Americans in the levels of and the rates of change in dental caries experience are clearly warranted.

As with all scientific endeavours, this research can be improved. Although our database involves 
as many as 4 repeated observations of a population-based sample of older Americans over a period of 5 years, it could be substantially expanded. For instance, in addition to older white and black Americans, Hispanic Americans and middle-aged respondents could be included. Furthermore, the period of observation could be extended. These enhancements would facilitate the analysis of longterm dental caries experience trajectories involving multiple racial/ethnic groups and birth cohorts, providing valuable information concerning the generalizability of our results. On the other hand, decayed teeth, missing teeth and filled teeth represent only a few of the dimensions of oral health. Other important dimensions may include, for example, periodontal diseases and dental healthrelated quality of life. Conceivably, trajectories of these outcome measures could be charted, and more importantly their dynamic linkages with the trajectories of decayed teeth, missing teeth and filled teeth need to be examined.

The present research is based on a variable-centred approach, which is predicated on the assumption that the population is homogeneous with respect to how the predictors operate on the outcomes. In contrast, a person-centred approach is based on the assumption that the population is heterogeneous with respect to how the predictors operate on the outcomes. For instance, using the group-based mixture models outlined by Nagin (39), Broadbent et al. (40) identified three distinct trajectories of dental caries experience measured by DMFS (decayed, missing and filled surfaces) up to age 32, although they did not focus on the effects of potential covariates. Further analysis of dental caries experience trajectories based on a personcentred approach would yield valuable information, particularly concerning the heterogeneity in changes in oral health over time.

In summary, decayed, missing and filled teeth exhibit distinct courses of change over time among older adults. Furthermore, older black Americans fare poorly relative to their white counterparts in the trajectories of dental caries experience. Racial disparities persist even when SES is taken into account.

\section{Acknowledgements}

This research was supported by grants R21 DE19518 and R01 DE08060 (Bei Wu, PI) from the National Institute of Dental and Craniofacial Research. We thank Corey Remle, Lina Bai and Lilly Y. Lee for their assistance in undertaking this research.

\section{References}

1. Lamster IB. Oral health services for older adults: a looming crisis. Am J Public Health 2004;94:699-702.

2. Pyle MA, Stoller EP. Oral health disparities among the elderly: Interdisciplinary challenges for the future. J Dent Educ 2003;67:1327-36.

3. Dye BA, Tan S, Smith V, Lewis BG, Barker LK, Thornton-Evans $\mathrm{G}$ et al. Trends in oral health status: United States, 1988-1994 and 1999-2004. Vital Health Stat 11 2007;248:1-92.

4. Ship JA, Ship II. Trends in oral health in the aging population. Dent Clin North Am 1989;33:33-42.

5. Institute of Medicine. Improving access to oral health care for vulnerable and underserved populations. Washington, DC: The National Academies Press; 2011.

6. Vargas CM, Yellowitz JA, Hayes KL. Oral health status of older rural adults in the United States. J Am Dent Assoc 2003;134:479-86.

7. Locker D. Deprivation and oral health: a review. Community Dent Oral Epidemiol 2000;28:161-9.

8. Sanders AE, Slade GD, Turrell G, Spencer AG, Marcenes $W$. The shape of the socioeconomic-oral health gradient: implications for theoretical explanations. Community Dent Oral Epidemiol 2006;34:310-9.

9. Watt RG. From victim blaming to upstream action: tackling the social determinants of oral health inequalities. Community Dent Oral Epidemiol 2007;35:1-11.

10. Kiyak HA, Kamoh A, Persson RE, Persson GR. Ethnicity and oral health in community-dwelling older adults. Gen Dent 2002;50:513-8.

11. Quandt SA, Chen H, Bell RA, Anderson AM, Savoca MR, Kohrman T et al. Disparities in oral health status between older adults in a multiethnic rural community: the rural nutrition and oral health study. J Am Geriatr Soc 2009;57:1369-75.

12. National Center for Health Statistics. National Health and Nutrition Examination Survey (NHANES) overview. Centers for Disease Control and Prevention; available at: http:/ / www.cdc.gov/ nchs/data/nhanes/nhanes_03_04/overviewbrochure_ 0304.pdf [last accessed 13 August 2009].

13. Wu B, Liang J, Plassman BL, Remle RC, Bai L. Oral health among white, black, and Mexican-American elders: an examination of edentulism and dental caries. J Public Health Dent 2011;71:308-317. doi: 10. $1111 /$ j.1752-7325.2011.00273.x

14. Griffin SO, Griffin PM, Swann JL, Zlobin N. New coronal caries in older adults: implications for prevention. J Dent Res 2005;84:715-20.

15. Thomson WM. Dental caries experience in older people over time: what can the large cohort studies tell us? Br Dent J 2004;196:89-92.

16. Rogosa DR. Myths about longitudinal research. In: Schaie KW, Campbell RT, Meredith WM, Rawlings $\mathrm{SC}$, editor. Methodological issues in aging research. New York: Springer Publishing, 1988; 171-209.

17. Patrick DL, Lee RSY, Nucci M, Grembowski D, Jolles CZ, Milgrom P. Reducing oral health disparities: a focus on social and cultural determinants. BMC Oral Health 2006;6(Suppl 1):S4-20. 
18. Petersen PE. Sociobehavioral risk factors in dental caries - international perspectives. Community Dent Oral Epidemiol 2005;33:274-9.

19. Crimmins EM, Hayward MD, Seeman TE. Race/ethnicity, socioeconomic status, and health. In: Anderson NB, Bulatao R, Cohen B, editor. Critical perspectives on racial and ethnic differences in health in late life. Washington, D.C.: The National Academies Press, 2004: 310-52.

20. Robert SA, House JS. Socioeconomic inequalities in health: An enduring sociological problem. In: Bird CE, Conrad P, Fremont AM, editor. Handbook of medical sociology, 5th edn. Upper Saddle River, N.J.: Prentice Hall, 2000; 79-97.

21. Graves RC, Beck JD, Disney JA, Drake CW. Root caries prevalence in black and white North Carolina adults over age 65. J Public Health Dent 1992;52:94-101.

22. Lawrence HP, Hunt RJ, Beck JD. Three-year root caries incidence and risk modeling in older adults in North Carolina. J Public Health Dent 1995;55:69-78.

23. Chen $X$, Clark JJ. Tooth loss patterns in older adults with special needs: a Minnesota cohort. Int J Oral Sci 2011;3:27-33.

24. Hunt RJ, Hand JS, Kohout FJ, Beck JD. Incidence of tooth loss among elderly Iowans. Am J Public Health 1988;78:1330-2.

25. Hand JS, Hunt RJ, Kohout FJ. Five-year incidence of tooth loss in Iowans aged 65 and older. Community Dent Oral Epidemiol 1991;19:48-51.

26. Lawrence HP, Beck JD, Hunt RJ, Koch GG. A method for adjusting the M-component of the DMFS Index for prevalence studies of older adults. Community Dent Oral Epidemiol 1996;24:322-31.

27. Drake CW, Hunt RJ, Koch GG. Three-year tooth loss among black and white older adults in North Carolina. J Dent Res 1995;74:675-80.
28. Raudenbush SW, Bryk AS. Hierarchical linear models, 2nd edn. Thousand Oaks, CA: Sage; 2002.

29. Long JS. Regression models for categorical and limited dependent variables. Thousand Oaks, CA: Sage; 1997.

30. Winship C, Mare RD. Regression models with ordinal variables. Am Sociol Rev 1984;49:512-25.

31. Raudenbush SW, Bryk AS, Congdon R. HLM - Hierarchical linear and nonlinear modeling (HLM). Lincolnwood, IL: Software International, Inc; 2008.

32. Schafer JL. Analysis of incomplete multivariate data. London: Chapman \& Hall; 1997.

33. Hunt RJ, Drake CW, Beck JD. Eighteen-month incidence of tooth loss among older adults in North Carolina. Am J Public Health 1995;85:561-3.

34. Hedeker D, Gibbons RD. Longitudinal data analysis. Hoboken, NJ: Wiley, 2006; 35.

35. Drake CW, Hunt RJ, Beck JD, Koch GG. Eighteenmonth coronal caries incidence in North Carolina older adults. J Public Health Dent 1994;54:24-30.

36. Drake CW, Beck JD, Lawrence HP, Koch GG. Threeyear coronal caries incidence and risk factors in North Carolina elderly. Caries Res 1997;31:1-7.

37. Lawrence HP, Hunt RJ, Beck JD, Davies G. Five-year incidence rates and intraoral distribution of root caries among community-dwelling older adults. Caries Res 1996;30:169-79.

38. Beck JD, Lawrence HP, Koch GG. Analytic approaches to longitudinal caries data in adults. Community Dent Oral Epidemiol 1997;25:42-51.

39. Nagin DS. Group-based modeling of development. Cambridge, MA: Harvard University Press, 2005.

40. Broadbent JM, Thomson WM, Poulton R. Trajectory patterns of dental caries experience in the permanent dentition to the fourth decade of life. J Dent Res 2008;87:69-72. 